\title{
Canadian Health Care Explained to U.S. Colleagues: the Good, the Bad and the Ugly
}

Can. J. Neurol. Sci. 2010; 37: 310-312

As I write this (late January, 2010) health care reform in the United States appears to be unraveling. An early and important objective of the Obama administration, ambitious reform legislation was passed by the House of Representatives in November of 2009 by a razor-thin majority, and on December 24, 2009, the Senate passed its own bill. Differences between the two bills were expected to be reconciled by both houses of Congress early this year and sent on to the White House. But Congressional Republicans have been united in opposition to the current bills, and the outcome of the Senatorial special election in the state of Massachusetts January 18, 2010, which resulted in the vacant seat created by Democrat Ted Kennedy's death being filled by Republican Scott Brown, means the Democrats have lost their 60-seat filibuster-proof supermajority. At this moment some hope still exists that a scaled-down version of the health reform bill can achieve bipartisan support, and President Obama vowed not to give up the fight in his January 27th State of the Union address. But the prognosis seems poor, and some Republicans are declaring the legislation already dead. If by the time you read this, the anti-reform movement has prevailed, and the proposed legislation has suffered the same fate as the 1993 Clinton health plan, many will have been left deeply disappointed. In all of the superb weekly coverage and commentary in the New England Journal's "Perspective" section over the past year (including opinion pieces from the Republican side $)^{1}$, no one has considered that the "status quo" in U.S. health care is feasible. Our southern friends and neighbors will be back at square one.

I was invited to give a talk describing Canadian Health Care to the American Congress of Neurological Surgeons in late October, 2009, a topic of considerable interest to them since back then it seemed possible that a little or maybe even a lot of our "public" health care system might be headed their way. The Scientific Program Committee Chair telephoned me several times leading up to the Congress requesting I not concentrate just on the qualities of our national health care system - they (my American colleagues) needed to "learn from our mistakes". The subtitle of my talk became "the good, the bad and the ugly".

I began by showing the audience (perhaps a thousand) what Canada looks like on a map, how it is divided up and where its population $(33,504,700$ in 2009) is distributed. (You probably know that most Americans know very little about Canada.) Since they were primarily neurosurgeons I informed them we have only about 220 practicing neurosurgeons in our vast nation (compared to nearly 3000 in the U.S.), with a ratio of roughly one neurosurgeon per 163,000 citizens. There are 22 neurosurgical centers in our country, 14 of which are training centers and only 4 of which are separate from a University or medical school center. They were very surprised (I determined from later discussion) to learn that the majority of Canadian neurosurgeons are now on salaried rather than "fee-for-service" reimbursement plans to provide comprehensive clinical coverage, teaching, program administration and research. Riveting to them (again from discussion that followed) was our mean gross annual income ( $\$ 550,000$, less, often considerably so, than theirs), our office and staff overhead costs (trivial compared to theirs), our mean income tax rates (not terribly different from theirs) and finally the malpractice scene in our country (much smaller than theirs, and defended by our own powerful Canadian Medical Protective Association, to which premiums are paid by our provincial governments - a very enviable situation as far as they are concerned!).

On to health care, and a description of our 1984 Federal Health Act for publicly funded health care insurance we call "Medicare" (the same name, incidentally, as the U.S.'s own Federally funded health insurance plan for citizens 65 years-ofage and older). The Canada Health Act has five central program criteria and requirements of the provinces and territories: 1) public administration (meaning not-for-profit), 2) comprehensive (plans must insure all medically necessary health services provided by doctors and hospitals), 3) universal (uniform terms \& conditions across our country), 4) portable (available wherever you are injured or sick in Canada), and 5) accessible (meaning "reasonable access" to health care services). The Canada Health Act guarantees that reasonable compensation is provided to health care providers, and in theory, but not in practice, it disallows "user charges" and "private clinics".

"Does 'socialized medicine' work?" I asked. Well (they were told), and at least in comparison to the U.S., it certainly does help contain health spending, which consumed roughly $11 \%$ of our GDP in 2009 (cf. 17\% in the U.S.), and amounts to roughly $\$ 5500$ per capita (cf. $\sim 7500$ in the U.S.) at the present time. Greater than $70 \%$ of health costs in Canada are hospital-based, with at least half of that budget allocated to wages. Health administrative costs in Canada are only a small fraction of those in the U.S. burdened as they are with a complex and wieldy private insurance industry.

But does our cheaper health care mean inferior health care compared to America? In fact better, it would appear, in terms of health outcomes ${ }^{2}$, overall performance, life expectancy and infant mortality ${ }^{3}$. According to the World Health Care Report, Canada ranks number 7 out of 40 countries in terms of "overall health attainment", compared to a ranking of \#15 for the United States $^{3}$.

My audience was also informed that as effective as our system is in containing health expenditures, it is still (and like 
their own), economically unsustainable, and in fact facing a funding crisis. Our provincial governments are struggling to streamline health care and make it more cost-effective. Initiatives, to name a few, include contracting services to private health care deliverers (a kind of "Americanization" of health care services), and making hospital funding and budget size "activitybased" (i.e. competitive) to stimulate increased efficiency and productivity. So far the savings have been modest. We in Canada struggle with the unavoidable reality: it is impossible to provide all possible health benefits to all people at all times, no matter how small the benefit and how great the cost. The solution is not at hand.

So what did I tell them about "the good, the bad, and the ugly" (as well as "the excellent") in the Canadian health care system?

\section{The Good}

First of all, urgent medical problems are given first priority in our country, without delay and without any type of government interference. There is necessary care and restraint when delivering elective medical services and interventions; hospitals and hospital care are "precious resources" and specialists are managers of our resources. Unproven and unnecessary procedures are simply unavailable in Canada. Spinal instrumentation, as an example, is performed at only a small fraction of rates witnessed in the U.S. In general neurosurgical practice it is not uncommon for patients to remove themselves from surgical waiting lists for cervical or lumbar diskectomies, their pain having resolved on its own. For some conditions, forced waiting ends up being a good thing!

\section{The Bad}

The inescapable downside of government-run health care is service rationing, from the number of hospital beds and workers to the number of operating rooms that are allowed to run on a daily basis. Doctors have little say in these matters. Instead rationing is strongly linked to downturns and upswings of the economy. This leads to limitations on "access to care" for nonurgent services, including imaging and tests, specialist consultations and elective surgical procedures. Costs are kept down, but waits and shortages result, which are stressful for patients as well as their caregivers who are left in the uncomfortable position of triaging according to relative need. There is no denying that access to health care is a number one concern of Canadian citizens.

\section{The Ugly}

There has been a misrepresentation of Canadian health care in the U.S. media, namely that patients with urgent problems have their lives at risk due to access to care barricades. This type of nonsense, including the appearance of a Canadian on the airwaves telling her story of a benign brain cyst she elected to have treated at the Mayo Clinic rather than wait several months for Canadian specialist consultations which her doctors felt necessary. She subsequently took legal action seeking reimbursement for her U.S. medical bills from her provincial health ministry, and this long before appearing in the U.S. media-even giving testimony before the American Congress, in what can be interpreted as nothing other than an attempt to advance her cause at home.

Another ugly mistruth propagated in the U.S. is that our government tells us how to practice medicine. Our governments provide budgets to our regional health care authorities to provide care, but care as we see fit. We must manage our resources as wisely and frugally as possible to provide best care, which we decide, not the "government".

\section{The Excellent}

The inarguable excellence of the Canadian health care system is that it is truly universal; every single Canadian citizen has complete coverage for necessary medical care. Compensation to providers for such service is legally guaranteed and virtually $100 \%$ retrievable. Relatively little money is wasted on administration (compared to the U.S.), meaning pretty good value for every health dollar spent. I also consider it excellent that however stressful and difficult, specialists are required to be careful managers of their precious hospital resources, ensuring appropriate testing and interventions. I have the greatest admiration for my colleagues that take this job seriously. And finally, there has, in our country, been a collective movement away from the incentives of the "fee for service" model. Quality, as opposed to quantity, should become the focus of medical practice.

So what ails health care in the United States? Uncontrollable and unsustainable costs, unfair and unacceptable private insurance practices resulting in millions upon millions of American citizens without health care coverage (a number, in total, greater than the population of Canada!), and the prospect of bankruptcy for individuals in the event of illness. As much as it is desperately needed, at the moment I write this the U.S. health care reform initiative is on life-support in the Senate. Opposition has been fierce, and from many fronts, not just private insurance lobbyists. "Government takeover", "budget-busting" legislation, and infringement on cherished American "freedom of choice", are common refrains. What has been particularly disappointing to me has been the strenuous opposition my American colleagues themselves have demonstrated. Not that I don't understand it! Specialist surgeons in the U.S. have an enviable work environment, with private "for-profit" hospitals eager to provide resources for expensive surgeries and interventions, and highly remunerative practices despite the hassles and costs dealing with private insurance companies. And for those Americans who actually have unrestricted medical coverage, a reformed system even remotely resembling the Canadian system with government involvement is deeply unsettling, indeed antithetical to the "American way". Those that have it (medical coverage) want it (medical care) exactly when they need it-the U.S. has the shortest waiting time for elective surgery in the world! Americans I have spoken to with good medical insurance are solidly opposed to current reform legislation, the perceived threat being less accessible (Canadian-style) health care combined with higher taxes to cover the currently uninsured and uninsurable citizens of the U.S.

Finally, a great irony is seldom mentioned in discussions with my American colleagues opposing a "government health care option". Despite resistance to a "public insurance option" in any type of reform package to date, all Americans are simply waiting 
to turn 65 so they can take advantage of American Medicare, a government-paid insurance program!

While I took pains to avoid sounding critical of colleagues' opposition to health care reform, I couldn't help concluding my talk with a slide of my kids lined up on skis on a sparkling "blue bird" day at Sunshine Village, Mount Assiniboine in the distance, accompanied by my comment that despite its shortcomings and deficiencies (which we Canadian doctors love to complain about), the truly best thing about health care in Canada is being able to live in our great country to receive it, and for us doctors, provide it.

\section{REFERENCES}

1. Curfman GD, Morrissey S, Malina D, Drazen JM. Better health outcomes for our citizens? Health Care Reform 2009 at healthcarereform.nejm.org. N Engl J Med. 2009; 361:709.

2. Guyatt GH, Devereaux PJ, Lexchin J, Stone SB, Yalnizyan A, Himmelstein D, et al. A systematic review of studies comparing health outcomes in Canada and the United States. Open Medicine. 2007; 1(1):1-2.

3. World Health Report 2000 - Health Systems: improving performance. Geneva, Switzerland: World Health Organization; 2000 . 